\title{
Digital Legacy: Posterity Rights Analysis and Proposed Model for Digital Memorabilia Adoption using Machine Learning
}

\author{
Amit Sudan ${ }^{1}$ \\ ME Scholar \\ Department of Computer Science Engineering \\ Chandigarh University, Mohali, India
}

\author{
Dr. Munish Sabharwal ${ }^{2}$ \\ Associate Dean \& Professor \\ Department of Computer Science Engineering \\ Chandigarh University, Mohali, India
}

\begin{abstract}
The paper informs about the digital legacy and its related concepts of posterity rights and digital memorabilia. It also deals with the right to exercise the digital posterity concerning the social networking profiles (SNP) on social networking sites (SNS). Digital Memorabilia is the compendium of people's social profiles and the digital artifacts accumulated in the name of people in online or virtual world, it can give people an online space to connect to and be remembered online even after their demise, showing the many dimensions of their real world personality. The paper proposes a model using multiple logistic regression technique of machine learning to predict the users that will opt for a digital memorial dependent upon different factors such as age, frequency of using SNPs, awareness about digital assets and digital legacy, awareness about privacy rights concerning digital assets and awareness about rights to posterity.
\end{abstract}

Keywords-Digital assets; digital legacy; digital posterity; digital executers; digital memorabilia; SNP (Social Networking Profiles); SNS (Social Networking Sites)

\section{INTRODUCTION}

From the past 10 years: demise, passing and online loss customs in the world are together forming an expanding field of attention in today's world [5]. Most of the research nowadays is nationally based and directed on discoursed examination of particular fields such as practices related to demise, interment traditions, and crypt traditions [9]. Although, in recent years, the area has expanded and has become more cross-punitive with the introduction of more networks across countries [1]. Work in online demise and memorial customs form a fast developing area of research, which directs on how death and misery are dealt with on several online platforms and social media such as Facebook, Twitter, etc. Moreover, this also questions how the online media [2] may be disguising our ways of mourning and harrowing. Every online platform has different features amongst which the online media share is one of the very important features for sharing and interacting with people whom we don't usually meet [8]. Now, we have entered into the social media phase, where people don't hesitate in uncovering truth and realities of their life to cite an example for the fame \#MeToo is a living example. In fact, people share all their emotions, grieve and show support to the people they favor [2]. These memorials also allow people to participate in their friends' and relatives' funeral process from any part of the world and at any time of the day or night [4]. In some sociologists' views, such people's exhibition of grief is significant for inner recuperation after deprivation [10]. Accessibility of low-cost or free space available online will allow pallbearer to include ample contents such as stories and discussions [15]. Facebook allows users with the chance to keep the deceased aside their lives by sharing posts on their walls during the birthdays and holidays in their lives or the grieving life [7]. These memorials also give the deprived the power to have the deceased's social media page if they want to be remembered of their good memories they once shared online with the deceased [12]. Continuous vows and conveying the feelings towards the person who are no more can be regarded as a remedy to the bereaved [14].

There is a need for a Digital Memorabilia of people's social presence in virtual space, which is a compendium of the digital artifacts of individual's online presence over a life span, showing the different facets of his personality and is live for an extended period, for the individual to be remembered for long on the online space by their friends.

In the following sections, we will focus on the previous works in the related area and the gap that is created by those research papers. The paper shows the technical aspect of the digital legacy: posterity rights and digital memorabilia by proposing a machine learning model using multiple logistic regression technique.

\section{LITERATURE REVIEW}

Sudan A. et al., 2019 [1], in their review paper have explained different categories of digital assets, social media types as well as the concept of digital legacy. They have also explained different contexts of privacy rights which are concerned about people's digital legacy and what should be done to their assets after their demise. The digital posterity explains the passing of all the assets to their digital executers after the demise of the person.

According to the author, Cerrillo-i-Martínez, A., 2018 [2], digital footprint consists of three mechanisms: legal certainty, effectiveness and transparency. They must also respect the desires communicated by the user, their digital executers and provide enough certainty to allow a digital resources user a 
never-ending rest in the online world. In the research paper of Peoples, C., \& Hetherington, M., 2015 [3], they had created a survey to capture perceptions of users on digital cloud footprints. The results of which shows that users are generally not aware about their digital footprints and digital legacy. The survey includes people of every age group and of different places who came from a range of employment backgrounds.

This part of literature focuses on user interface frameworks and models designed for the digital legacy and its associated technologies. Byrd G., 2016 [4] in his study shows the highlevel interaction between the digital legacy user interface, its users and the other online services such as cloud services. He made a functional design where users can add an account, amend an account, add a site, etc. Users can manage their account such as password and other information related to it. Users can also have an option to design their own digital memorial page where they can record their information. Whittaker, S., Bergman, O., \& Clough, P., 2010 [5] in their paper have examined the effects of technologies related to digital photography which people had stored online for longer term. Due to poor organization of the digital contents, this study performed poorly. Another framework that ensures people to understand how to protect and pass on their digital legacy to their digital executers is given by Norris, J., \& Taubert, M., 2016 [6]. The authors have made six steps framework that is associated with digital assets and digital end of life. It shows three categories which are digital assets, connected devices and digital legacy. In the field of digital legacy, another authors named Gulotta, R., Faste, H., \& Forlizzi, J. (2012) [7] have created a tool called Revelado where users can store their information online so that their information can be accessed by their future generations and be remembered online forever. Kang, Y. S., \& Lee, H., 2010 [8], brings out the author's attempt to propose a model to find out customer's satisfaction so as to design some investment strategy of retaining customers.

Some studies have highlighted the importance of public thoughts and reviews about digital legacy and posterity rights. Waagstein, A., 2014 [9] has collected data in the form of questionnaires mostly in semi-structured form. The questions were mostly related to digital legacy and digital artifacts. The authors concludes by discovering patterns and by making a summary of the interviews performed and in-depth readings were performed on some statements. The study by Gulotta, R., et al., 2013 [10] brings out the viewpoint of parents and focuses on finding the point of view of parents about the passing of digital materials in future. On the basis of their responses a system can be designed that can be used as provocative and speculative artifacts. The author had used diagrams and themes to interpret the findings. In the view of college students, Pempek, T. A. et al., 2009 [11], have highlighted experiences of college students of social networking on Facebook. They have proposed different factors such as frequency of Facebook by college students, gender, etc. They conducted surveys to find out the purpose of using Facebook by these college students. Another work which was done on this is by Massimi, M., \& Baecker, R. M., 2010 [12] where the authors have presented the survey in the form of questionnaires to examine the use of technology and other digital techniques to remember the deceased. Correa, T., et al., 2010 [13] shows the relationship between social media and personality predictors with respect to various factors such as gender, age, etc. The author has proposed various hypotheses in response to social media and personality predictors. These hypothesis are extraversion, emotional stability and openness. Both the personality predictors and social media showed how much these hypotheses have had an impact related to digital media. Petrelli, D., \& Whittaker, S., 2010 [14] have conducted some fieldwork and compare the physical and digital work. They concluded the work with some digital limitations and design guidelines associated with it. Rubin, H. J., \& Rubin, I. S., 2011 [15], in their book have conducted qualitative interviews to identify the gathering style of data. They describe detailed qualitative interviewing to underline philosophy related to project design and analysis.

This section of literature focused on the various factors related to social networking sites and social networking profiles. Lin, K. Y., \& Lu, H. P., 2011 [16], the authors have focused on various factors that affects user's joining social networking sites by applying some network externalities and motivation theory. This is applied to find out why people are that desperate to join social networking sites. The factors involved here are age, gender, occupation, education and Facebook services. To find the reason behind the increase in usage of social media, the authors Lee, J., \& Suh, E., 2013 [17] have used three theories to examine people's characteristics. These theories are Technology Acceptance Model (TAM), Innovation Diffusion Theory (IDT) and Network externality. Based on these theories, they find out some positive significant effects of SNS. In another research Sago, B., 2013 [18], has highlighted the various factors that influence adoption of social media and frequency. He examined the adoption factors for four platforms Facebook, Pinterest, Twitter, Google+ and the factors used are awareness, enjoyment, knowledge, reasons used, usefulness and ease of use. Kane GC et al., 2009 [19], in their study have stated the importance of social media in person's life. They highlighted how the social media platforms promote relationships. The authors have taken the example of health care industry to show the importance of social media platforms. Munish Sabharwal et al., 2012 [20] conducted a study with the objective to find out whether the selected Indian scheduled banks have presence on the Social Networking Media or not.

Few studies also focus on the life of famous media personalities after death, Sherlock, A., 2013 [21] has stated the reason and importance of conservation of famous personalities and the effect of social media on their careers. Even after their death, their followers will not go unwane due to digital technologies proposed by the author.

This section review studies highlighting the importance of digital artifacts in relation to digital legacy and the problems associated with it. Banks, R., 2011 [22] has highlighted the importance of managing the digital artifacts and also explans how to inherit those contents in the future. He wants to explore the technology that could help the people realize their potential. In another article, Banks, R., Kirk, D., \&Sellen, A., 2012 [23] state the importance of artifacts in the life of people 
as it can act as a trigger to remember someone after his demise. They highlighted on such artifact in this paper which is their heirloom. In this paper they suggested a design case study for the process of inheriting person's assets.

The study by the authors Romano, J. et al., 2011 [24] have focused on the life they have lived even after their death. They have thrown the light on the life of the person after their demise but online. They have pointed out different plans such as what could be done for the artifacts left behind by the person.

The next' two papers discuss the privacy rights of digital legacy. Edwards, L., \& Harbina, E., 2013 [25], in their article have emphasized on the privacy rights of digital legacy of the deceased. They have given different defamation and moral rights for the regulation of post-mortem privacy. Gotved, S., 2014 [26] have offered a systematic way to keep track of people's timeline and their digital context related to physical death of the person. Bellamy, C. et al., 2013 [27] has pointed out the difficulties which are involved in conserving and leaving digital legacy online after the demise of a person. They pointed out several problems related to digital legacy, one of which is passing on digital music and books as it could lead to copyright issues. The next paper focuses on the sentiments and artifacts of the person, Kirk, D. S., \& Sellen, A., 2010 [28] highlighted the sentiments and artifacts related to the person and the nature of thing. The authors explained the practices to keep sentimental artifacts of the person. Wiegand, D. L. M. et al., 2008 [29] in their article address issues related to dying research. They imposed some challenges related to informed consent, data collection, etc.

This part of literature describes the different memorialization practices and issues dealing with it. Walter, T. et al., 2012 [30] research is divided into two parts; the first part explains the practices related to dying and memorialization and the second part describes the concepts related to these practices. Odom, W. et al., 2010 [31], this paper describes the problems and issues about death and memorialization. The authors conducted in-depth interviews about the issues related to bereavement.

The result of the above literature is that most of the papers talked about the survey concerning the awareness of digital legacy of the people, whereas some of them talked about designing some digital memorial of people using their social networking profiles but none of them pointed out the technical aspect related to the digital legacy: digital posterity and digital memorabilia.

The studies by Munish, first [32], facilitated the researcher in overall preparation of literature review and planning for the overall research and the second [33], assisted in analysis.

\section{METHODOLOGY}

\section{A. Data Collection}

To get people's opinion with regard to digital awareness, a questionnaire is made and has been distributed in the form of survey on the basis of different age groups, gender and different online platforms the respondents engage in.
The data used for this study were collected by forming the questionnaires related to different aspects of digital legacy such as the first section answers their personal questions, the second answers the matter related to digital legacy and the privacy rights related to digital legacy and the third answers the matter of the digital posterity and rights concerning their digital posterity. The questionnaires were distributed to people of different age groups and of different fields through Google forms. Based on the data, a model would be created for digital memorial of people based on their social networking profiles.

\section{B. Analysis}

The bar chart between posterity rights vs. age group is as follows in Fig. 1.

Below are the summarized responses in the form of pie charts and bar charts which we got from the questionnaires distributed through Google forms over the web which is shown in below figures from Fig. 2 to Fig. 13.

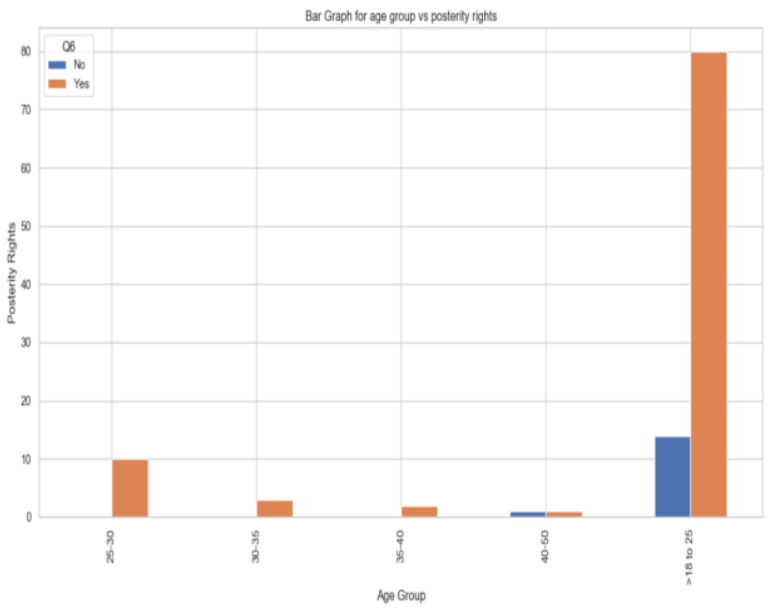

Fig. 1. Bar chart between Age Group and Posterity Rights.

Q1.)For which of the following purposes do you use IT devices(PC, Tablets, Smart Phones etc)and internet:

111 responses

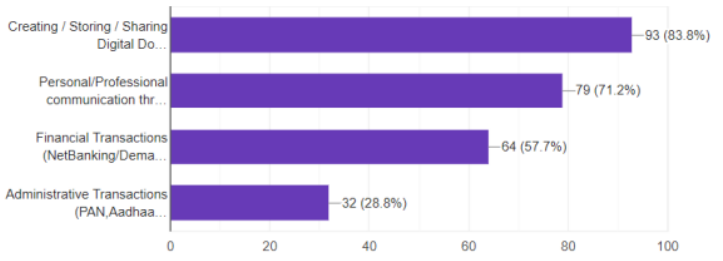

Fig. 2. Response of People: Purpose of using IT Devices.

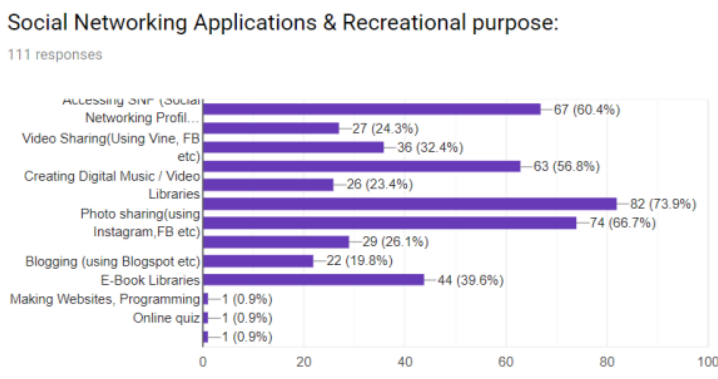

Fig. 3. Response of People: Social Networking Applications. 


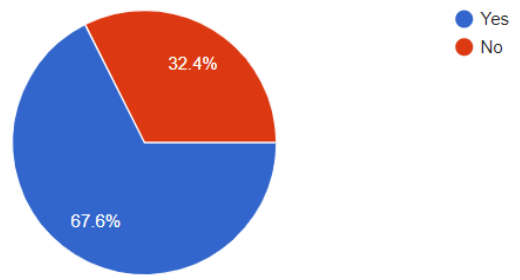

Awareness of Digital Assets and Digital Legacy

Fig. 4. Response of People: Awareness of Digital Assets and Digital Legacy.

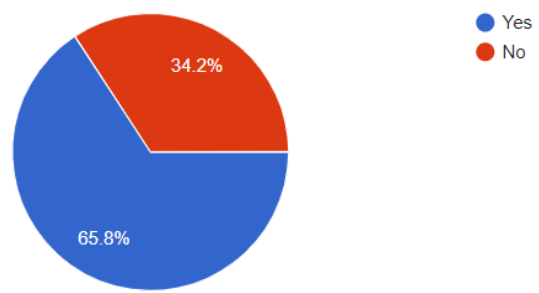

Awareness of Privacy Rights of Digital Assets

Fig. 5. Response of People: Awareness of Privacy Nights of Digital Assets.

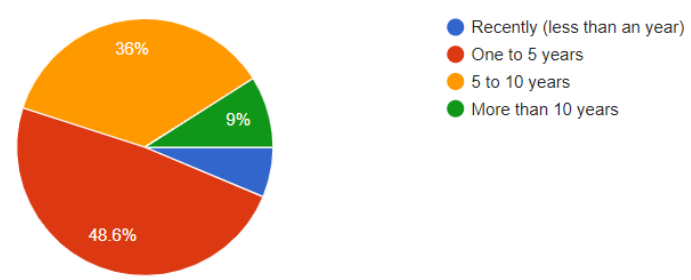

Creation of First SNP

Fig. 6. Response of People: Creation of First SNP.

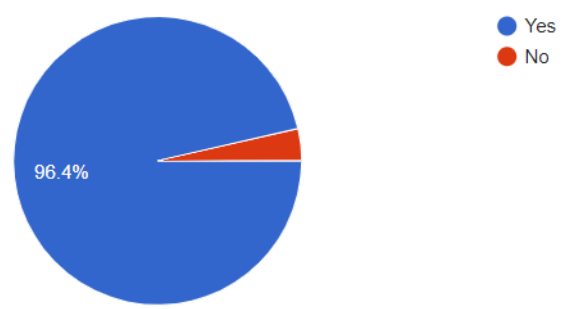

Percentage of Respondents having SNP

Fig. 7. Response of People: Percentage of Respondents having SNP.

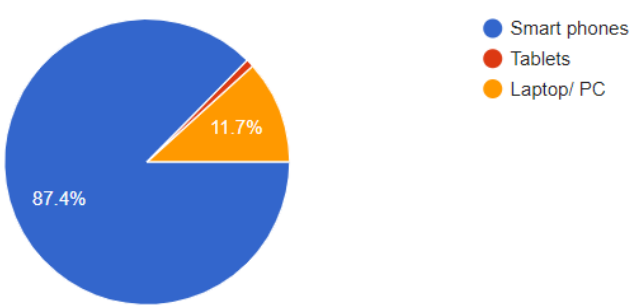

Type of Device to Access SNP

Fig. 8. Response of People: Type of Device to Access SNP.

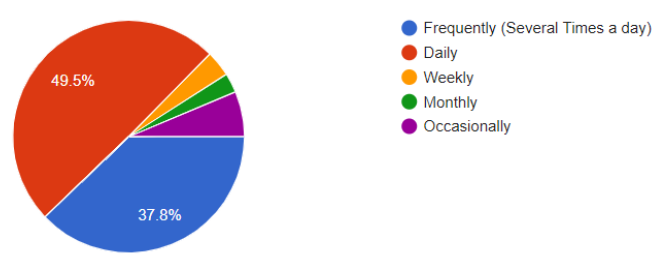

Frequency of Accessing SNP

Fig. 9. Response of People: Frequency of Accessing SNP.

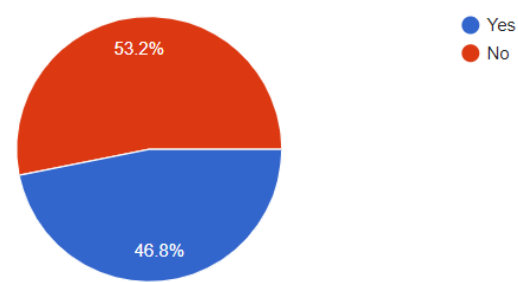

Awareness of Right to Posterity

Fig. 10. Response of People: Awareness of Right to Posterity.

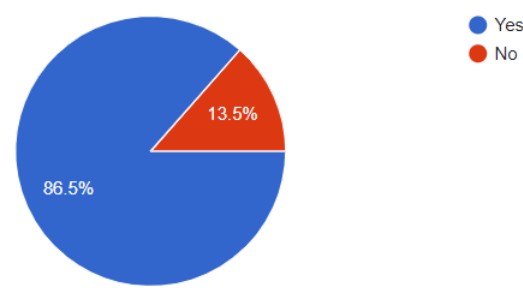

Percentage of Respondents to Exercise Right to Posterity

Fig. 11. Response of People: Percentage of Respondents to Exercise Right to Posterity.
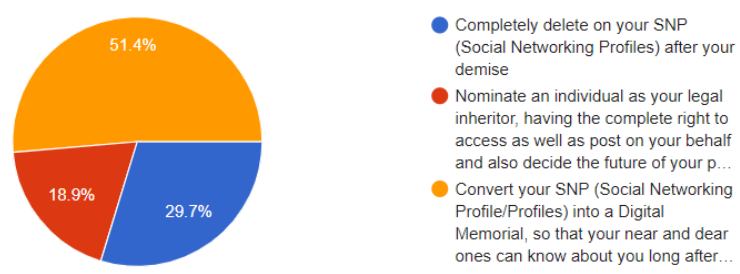

Options to Exercise Right to Posterity

Fig. 12. Response of People: Options to Exercise Right to Posterity.

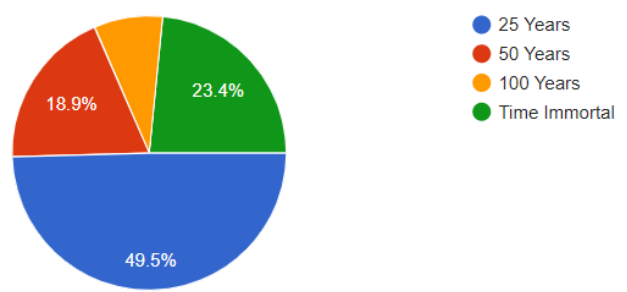

Time Period of SNP

Fig. 13. Response of People: Time Period of SNP. 


\section{RESULTS AND DisCUSSIONS}

To assess the people's opinion on posterity rights, we had performed logistic regression analysis to predict a machine learning model from the data set we have got from Google forms.

First step was to identify dependent and independent variables. We will take dependent variable a categorical data in the form of YES or NO as if given an opportunity, would you like to exercise your rights to posterity (it is about announcing in advance what should be done with your SNPs or deciding the legal inheritor of your SNPs).

The independent variables were taken after analyzing the responses from respondents and factors such as age, frequency of using SNPs, awareness about digital assets and digital legacy, awareness about privacy rights concerning digital assets and awareness about rights to posterity from the given set of variables from the dataset were chosen as independent variables.

We applied multiple logistic regression to predict the relationship between posterity rights and various independent variables one of them being taken as age group.

Multiple Logistic Regression was applied on the collected dataset using Anaconda framework with Python with SciKit learn API.

The result of the logistic regression is given below in Fig. 14.

Below is the classification report of the model shown in Fig. 15.

\begin{tabular}{|c|c|c|c|c|c|c|}
\hline \multicolumn{7}{|c|}{$\begin{array}{l}\text { Optimization terminated successfully. } \\
\text { Current function value: } 0.3468 \\
\text { Iterations } 7 \\
\text { Results: Logit }\end{array}$} \\
\hline Model: & \multicolumn{2}{|c|}{ Logit } & \multicolumn{2}{|c|}{ Pseudo R-squared: } & \\
\hline Dependent Variable: & \multicolumn{2}{|c|}{$\mathrm{y}$} & \multicolumn{2}{|c|}{ AIC: } & \multicolumn{2}{|c|}{$\begin{array}{l}0.086 \\
64.3582\end{array}$} \\
\hline Date: & \multicolumn{2}{|c|}{$2019-04-08 \quad 21: 15$} & \multicolumn{2}{|c|}{ BIC: } & \multicolumn{2}{|c|}{$\begin{array}{l}64.3582 \\
69.2900\end{array}$} \\
\hline No. Observations: & \multicolumn{2}{|c|}{87} & \multicolumn{2}{|c|}{ Log-Likelihood: } & \multicolumn{2}{|c|}{-30.179} \\
\hline Df Model: & \multicolumn{2}{|l|}{1} & \multicolumn{2}{|c|}{ LL-Null: } & \multicolumn{2}{|c|}{$\begin{array}{l}-30.179 \\
-33.021\end{array}$} \\
\hline Df Residuals: & \multicolumn{2}{|l|}{85} & \multicolumn{2}{|l|}{ LLR p-value: } & \multicolumn{2}{|c|}{0.017114} \\
\hline Converged: & \multirow{2}{*}{\multicolumn{2}{|c|}{$\begin{array}{l}1.0000 \\
7.0000\end{array}$}} & \multicolumn{2}{|l|}{ Scale: } & \multirow{2}{*}{\multicolumn{2}{|c|}{1.0000}} \\
\hline No. Iterations: & & & & & & \\
\hline Coef. & td.Err. & $z$ & $\mathrm{P}>|\mathrm{z}|$ & {$[0.02$} & & $0.975]$ \\
\hline 2.1619 & 0.7481 & 2.8900 & 0.0039 & 0.695 & & 3.6281 \\
\hline 1.8335 & 0.4846 & 3.7831 & 0.0002 & 0.883 & & 2.7833 \\
\hline
\end{tabular}

Fig. 14. Result of Multiple Logistic Regression.

$\begin{array}{rrrrr} & \text { precision } & \text { recall } & \text { fl-score } & \text { support } \\ 0 & 0.00 & 0.00 & 0.00 & 5 \\ 1 & 0.81 & 1.00 & 0.90 & 22 \\ & & & & \\ \text { micro avg } & 0.81 & 0.81 & 0.81 & 27 \\ \text { macro avg } & 0.41 & 0.50 & 0.45 & 27 \\ \text { weighted avg } & 0.66 & 0.81 & 0.73 & 27\end{array}$

Fig. 15. Computation of other Parameters Such as Precision, Recall, FMeasure and Support based on Factors.

\section{CONCLUSION}

The accuracy of the model is $81 \%$. So, the model we have predicted has done fairly well. The study results indicated that our research model reveal good descriptive ability to predict user's persistent purpose whether to exercise their rights to posterity or not under various factors such as age, frequency of using SNPs, awareness about digital assets and digital legacy, awareness about privacy rights concerning digital assets and awareness about rights to posterity, giving a new way for researchers to inspect in future research work in related areas.

\section{FUTURE SCOPE}

The data set can be large so that more accurate model can be predicted in future and to get high accuracy, we can apply other technique other than regression.

Further research should endeavor to acquire more samples for more various SNS user type to validate our research model and to examine the differences among users. Moreover, we can add more factors or constructs such as self-efficacy, altruism etc. to give model a more precise view.

\section{ACKNOWLEDGMENT}

This is to show my profound gratitude to Dr. Munish Sabharwal, Associate Dean \& Professor, Department of Computer Science Engineering, Chandigarh University, India for always motivating me to learn. I am sincerely thankful to him for guiding and instructing me through the entire research work and for being my mentor.

\section{REFERENCES}

[1] Sudan A et.al (2019). Privacy rights for digital assets and digital legacy right for posterity: A Survey has presentated in 2nd International Conference on Data \& Information Sciences on March 29-30, 2019 given at Raja Balwant Singh Engineering Technical Campus, Bichpuri, Agra, Uttar Pradesh, INDIA.

[2] Cerrillo-i-Martínez, A. (2018). How do we provide the digital footprint with eternal rest? Some criteria for legislation regulating digital wills. Computer Law \& Security Review.

[3] Peoples, C., \& Hetherington, M. (2015, November). The cloud afterlife: Managing your digital legacy. In Technology and Society (ISTAS), 2015 IEEE International Symposium on (pp. 1-7). IEEE.

[4] Byrd, G. (2016). Immortal Bits: Managing Our Digital Legacies. Computer, (3), 100-103.

[5] Whittaker, S., Bergman, O., \& Clough, P. (2010). Easy on that trigger dad: a study of long term family photo retrieval. Personal and Ubiquitous Computing, 14(1), 31-43.

[6] Norris, J., \& Taubert, M. (2016). P-221 Working with hospices to ensure patients' digital legacy wishes are adhered to.

[7] Gulotta, R., Faste, H., \& Forlizzi, J. (2012). Revelado: Exploring the Preservation of our Digital Data.

[8] Kang, Y. S., \& Lee, H. (2010). Understanding the role of an IT artefact in online service continuance: An extended perspective of user satisfaction. Computers in Human Behavior, 26(3), 353-364.

[9] Waagstein, A. (2014). An exploratory study of digital legacy among death aware people. Thanatos, 3(1), 46-67.

[10] Gulotta, R., Odom, W., Forlizzi, J., \& Faste, H. (2013, April). Digital artifacts as legacy: exploring the lifespan and value of digital data. In Proceedings of the SIGCHI Conference on Human Factors in Computing Systems (pp. 1813-1822). ACM.

[11] Pempek, T. A., Yermolayeva, Y. A., \& Calvert, S. L. (2009). College students' social networking experiences on Facebook. Journal of applied developmental psychology, 30(3), 227-238. 
[12] Massimi, M., \&Baecker, R. M. (2010, April). A death in the family: opportunities for designing technologies for the bereaved. In Proceedings of the SIGCHI conference on Human Factors in computing systems (pp. 1821-1830). ACM.

[13] Correa, T., Hinsley, A. W., \& De Zuniga, H. G. (2010). Who interacts on the Web? The intersection of users' personality and social media use. Computers in Human Behavior, 26(2), 247-253.

[14] Petrelli, D., \& Whittaker, S. (2010). Family memories in the home: contrasting physical and digital mementos. Personal and Ubiquitous Computing, 14(2), 153- 169.

[15] Rubin, H. J., \& Rubin, I. S. (2011). Qualitative interviewing: The art of hearing data. Sage.

[16] Lin, K. Y., \& Lu, H. P. (2011). Why people use social networking sites: An empirical study integrating network externalities and motivation theory. Computers in human behavior, 27(3), 1152-1161.

[17] Lee, J., \& Suh, E. (2013). An Empirical Study of the Factors Influencing Use of Social Network Service. In PACIS (p. 181).Munish Sabharwal et. al, "Indian Banks: Presence and Interactivity level on Social Networking Media", IFRSA Business Review, ISSN (Online): 2249-5444 ISSN (Print): 2249-8168 Impact factor (2012): 0.1351, Vol. 2 Issue 4, pp.360365, Dec 2012.

[18] Sago, B. (2013). Factors influencing social media adoption and frequency of use: An examination of Facebook, Twitter, Pinterest and Google+. International Journal of Business and Commerce,3(1),1-14.

[19] Kane, G. C., Fichman, R. G., Gallaugher, J., \& Glaser, J. (2009). Community relations 2.0. Harvard business review, 87(11), 45-50.

[20] Munish Sabharwal et. al, "Indian Banks: Presence and Interactivity level on Social Networking Media", IFRSA Business Review, ISSN (Online): 2249-5444 ISSN (Print): 2249-8168 Impact factor (2012): 0.1351, Vol. 2 Issue 4, pp.360- 365, Dec 2012.

[21] Sherlock, A. (2013). Larger than life: Digital resurrection and the reenchantment of society. The Information Society, 29(3), 164-176.

[22] Banks, R. (2011). The future of looking back (Microsoft Research). Microsoft Press.
[23] Banks, R., Kirk, D., \&Sellen, A. (2012). A design perspective on three technology heirlooms. Human-Computer Interaction, 27(1-2), 63-91.

[24] Romano, J. (2011). Your Digital Afterlife: When Facebook, Flickr and Twitter Are Your Estate, What's Your Legacy? New Riders.

[25] Edwards, L., \&Harbina, E. (2013). Protecting post-mortem privacy: Reconsidering the privacy interests of the deceased in a digital world. Cardozo Arts \& Ent. LJ, 32, 83.

[26] Gotved, S. (2014). Research Review: Death Online-Alive and Kicking!. Thanatos, 3(1/2014).

[27] Bellamy, C., Arnold, M., Gibbs, M., Nansen, B., \& Kohn, T. (2013). Life beyond the timeline: creating and curating a digital legacy. In meeting of Prato Community Informatics Research Network (CIRN), Prato, Italy.

[28] Kirk, D. S., \&Sellen, A. (2010). On human remains: Values and practice in the home archiving of cherished objects. ACM Transactions on Computer-Human Interaction (TOCHI), 17(3), 10.

[29] Wiegand, D. L. M., Norton, S. A., \& Baggs, J. G. (2008). Challenges in conducting end- of-life research in critical care. AACN Advanced Critical Care, 19(2), 170-177.

[30] Walter, T., Hourizi, R., Moncur, W., \&Pitsillides, S. (2012). Does the internet change how we die and mourn? Overview and analysis. OMEGA-Journal of Death and Dying, 64(4), 275-302.

[31] Odom, W., Harper, R., Sellen, A., Kirk, D., \& Banks, R. (2010, April). Passing on \& putting to rest: understanding bereavement in the context of interactive technologies. In Proceedings of the SIGCHI conference on Human Factors in computing systems (pp. 1831-1840). ACM.

[32] Sabharwal, M. (2016, March). Contemporary research: intricacies and aiding software tools based on expected characteristics. In 10th National Research Conference on Integrating Technology in Management Education, AIMA, New Delhi (pp. 28-29).

[33] Sabharwal, M. (2018). The Use of Soft Computing Technique of Decision Tree in Selection of Appropriate Statistical Test For Hypothesis Testing. In Soft Computing: Theories and Applications (pp. 161-169). Springer, Singapore. 